\title{
2,4-Diacetylphloroglucinol suppresses zoosporogenesis and impairs motility of Peronosporomycete zoospores
}

\author{
M. Tofazzal Islam • Andreas von Tiedemann
}

Received: 22 November 2010/Accepted: 20 January 2011/Published online: 2 February 2011

(C) Springer Science+Business Media B.V. 2011

\begin{abstract}
Diacetylphloroglucinol (DAPG) produced by Pseudomonas fluorescens, shows toxicity to many microorganisms including fungi, bacteria, and peronosporomycetes. Zoosporogenesis and motility of zoospores are critical for a complete disease cycle and pathogenicity of the peronosporomycete phytopathogens. The aim of this study was to test the effects of DAPG and its derivatives on zoosporogenesis and motility of zoospores of a downy mildew pathogen, Plasmopara viticola, and a damping-off pathogen, Aphanomyces cochlioides. In both cases, DAPG inhibited zoosporogenesis $(5 \mu \mathrm{g} / \mathrm{ml})$ and the motility of zoospores $(10 \mu \mathrm{g} / \mathrm{ml})$ in a dose-dependent manner. Generally, zoospores became immotile shortly after exposure to DAPG followed by lysis. However, a fraction of DAPG treated A. cochlioides zoospores formed round cystospores instead of lysis and then germinated with excessivelybranched germ tubes. All derivatives of DAPG had similar inhibitory activities but at varying doses. Among them, 2,4dipropylphloroglucinol exerted the highest inhibitory activity against both zoosporogenesis and motility of zoospores. This revealed that the degree of hydrogen atoms substitution in the benzene ring by acyl groups and the length of substituted acyl groups were related to the level of bioactivity. This is the first report of inhibitory activities of DAPG and its derivatives against zoosporogenesis and motility of zoospores of two important peronosporomycete phytopathogens.
\end{abstract}

M. T. Islam · A. von Tiedemann

Division of Plant Pathology and Plant Protection, University

of Göttingen, Grisebachstrasse 6, Göttingen, Germany

M. T. Islam ( $\square)$

Department of Biotechnology, Bangabandhu Sheikh Mujibur Rahman Agricultural University, Gazipur 1706, Bangladesh e-mail: tofazzalislam@yahoo.com
Keywords Zoosporogenesis .

2,4-Dipropylphloroglucinol - Oomycetes · Zoosporicides · Plasmopara viticola $\cdot$ Aphanomyces cochlioides

\section{Introduction}

The polyketide antibiotic, 2,4-diacetylphloroglucinol (DAPG) produced by several strains of the biocontrol bacterium, Pseudomonas fluorescens, has been shown a broad-spectrum toxicity to organisms such as bacteria, fungi, protists, nematodes and peronosporomycetes (Bender and Rangaswamy 1999; Bangera and Thomashow 1999; Isnansetyo et al. 2003; de Souza et al. 2003a; Kamei and Isnansetyo 2003; Islam and Fukushi 2010). A large body of literature suggests that the biocontrol efficacy of $P$. fluorescens is largely linked to the production of DAPG (Dwivedi and Johri 2003; Paulsen et al. 2005; Weller et al. 2007). The toxicity of DAPG to diverse groups of organisms suggests that its targets may include varities of cellular processes such as lysis of bacterial cells by novel antibiotic mechanisms (Kamei and Isnansetyo 2003), alterations of plant root development (Brazelton et al. 2008), improvement of crop health by seed treatment with DAPG (Raudales et al. 2009), disruption of the organization of cytoskeletal filamentous actin in Aphanomyces cochlioides hyphae (Islam and Fukushi 2010), and impairment of mitochondrial function in the yeast Saccharomyces cerevisae (Gleeson et al. 2010). It has been demonstrated that the osmotrophic amoeba Vahlkampfia sp. lost motility within $1 \mathrm{~min}$ of exposure to DAPG followed by lysis within $1 \mathrm{~h}$ (Jousset et al. 2006). DAPG has also been shown to inhibit mycelial growth and asexual sporulation of a soilborne phytopathogenic peronosporomycete, Pythium 
ultimum var. sporangiferum, through alteration of the plasma membrane, vacuolization, and the disintegration of hyphal cell contents (de Souza et al. 2003a).

Although toxicity of DAPG to a broad range of organisms has been documented in many reports, the mode of action of this well-known antimicrobial agent is still poorly understood. Scant information is available on the structurefunction relationships for biological activities shown by this polyketide antibiotic. Recently, we demonstrated that mycelial growth inhibited by DAPG and its producing bacterium, $P$. fluorescens, is linked to the disruption of cytoskeletal filamentous actin organization in the hyphal cells of a damping-off pathogen, A. cochlioides (Islam and Fukushi 2010). Although DAPG has been shown inhibitory activity towards several soilborne fungi and peronosporomycetes, little is known on its effect on the foliar pathogens of obligate biotrophic downy mildews.

The peronosporomycete genera such as Phytophthora, Plasmopara, Aphanomyces, and Pythium are devastating pathogens of plants, animals, fishes and even humans (Agrios 1997). Generally, they infect their hosts through asexually produced characteristic biflagellate motile zoospores (Islam and Tahara 2001). The zoospores locate infection sites on their host guided by host cues and then rapidly change into round cystospores followed by germination to form hyphal germ tubes and initiate infection (Islam and Tahara 2001). Disruption of any of these asexual life stages eliminates infection (Judelson and Blanco 2005). Among the peronosporomycetes, the obligate biotrophic pathogen Plasmopara viticola is a most notorious one causing downy mildew disease in grapevine worldwide (Agrios 1997). This fungus-like microorganism spreads very rapidly through asexually produced airborne sporangia which release biflagellate motile zoospores on the surface of wet grapevine leaves (Riemann et al. 2002). The motile zoospores locate stomata guided by the host cues and then differentiate into round cystospores, which germinate to form germ tubes and to invade leaf tissues (Kiefer et al. 2002). Due to its obligate nature, $P$. viticola is recalcitrant to cultivation on culture media which strongly hampers the in vitro production of sufficient amounts of zoospores and restricts the representation of other asexual life stages in vitro. Therefore, our knowledge on the underlying molecular mechanisms of the asexual development in this downy mildew pathogen is limited. Recently, we developed convenient methods for production of copious amounts of sporangia and zoospores of $P$. viticola in host-free systems (Islam and Tiedeman 2008). These methods have allowed us to test DAPG and related compounds with regard to zoosporogenesis and motility of $P$. viticola zoospores.

In contrast, A. cochlioides Drechsler is a soilborne peronosporomycete, which causes devastating damping-off diseases in spinach, sugar beet and some other members of Chenopodiaceae and Amaranthaceae. Unlike the downy mildew pathogens, A. cochlioides abundantly produces primary zoospores in vitro from the cylindrical sporangia, which become encysted immediately after their release (Islam and Tahara 2001). The biflagellate motile secondary zoospores released from the primary cysts are thought to be the infectious agents, which locate their host guided by a host-specific flavone (5-hydroxy-6,7-methylenedioxyflavone) that exudes from the roots (Islam and Tahara 2001).

As the process of release of zoospores from sporangia (zoosporogenesis) and the motility of the released zoospores are critical for disease cycles and pathogenicity of the peronosporomycete phytopthogens, we tested the effects of DAPG and its derivatives on these two key stages in the asexual life cycle of two different peronosporomycete phytopathogens, P. viticola and A. cochlioides. The specific objectives of this research were to (1) test effects of DAPG and its derivatives on zoosporogenesis i.e., release of zoospores from the sporangia; to (2) evaluate the effects of DAPG and its derivatives on the motility and viability of zoospores and to (3) make an attempt to link the molecule structure to biological activities.

\section{Materials and methods}

Microbial organisms and production of zoospores

Sporangia of Plasmopara viticola were isolated from infected leaves of grapevine (Vitis vinifera cv. MüllerThurgau) received from Prof. Beate Berkelmann, Geisenheim Research Center, Germany. This strain was originally gained from infected leaf materials of the grapevine cv. Riesling in 1996 and since then propagated on fresh leaves of Müller-Thurgau. We maintained this strain by regular sub-culturing on the lower surface of young grapevine leaves in Petri dishes containing $1.5 \%$ agar at $25^{\circ} \mathrm{C}$ and $95 \%$ relative humidity (Islam and Tiedeman 2008). At day 6 of cultivation, the sporangiophores bearing lemon-shaped sporangia were harvested into an eppendorf tube by a micro-vacuum cleaner. The freshly harvested sporangia were separated from the sporangiophores by filtration through $50 \mu \mathrm{m}$ nylon meshes, washed twice and then incubated in sterilized water $\left(3 \times 10^{4}\right.$ sporangia/ml $)$ in the dark for $6 \mathrm{~h}$ at room temperature $\left(23^{\circ} \mathrm{C}\right)$ to release zoospores. These zoospores remained motile up to $15 \mathrm{~h}$ in sterilized water at room temperature and were used for bioassays.

The damping-off pathogen of sugar beet, Aphanomyces cochlioides, obtained from the Sugar Beet Research Institute (IFZ) in Goettingen, Germany, was grown in corn meal agar medium (CMA, $17 \mathrm{~g} / \mathrm{l}$, Difco Laboratories, 
Sparks, MD, USA) in the plastic petri dishes ( $9 \mathrm{~cm}$ i.d.) for $5-6$ days at $23^{\circ} \mathrm{C}$. The zoospores were produced according to the protocol described earlier (Islam and Tahara 2001).

\section{Chemicals}

Phloroglucinol (PG), monoacetylphloroglucinol (MAPG), 2,4-diacetylphloroglucinol (DAPG), 2,4,6-triacetylphloroglucinol (TAPG) and 2,4-dipropylphloroglucinol (DPPG) (Fig. 1) were synthesized (Marchand et al. 2000) and kindly provided by Dr. Yukiharu Fukushi of Hokkaido University, Japan.

\section{Bioassays}

Stock solutions of DAPG and its derivatives were prepared in small amounts of dimethyl sulfoxide (DMSO). Then a series of concentrations of each compound was prepared in distilled water. The bioassays for zoosporogenesis and motility of zoospores were carried out following protocols described earlier (Islam et al. 2002, 2004; Islam and Tiedeman 2008). Briefly, $40 \mu \mathrm{l}$ of sample solution in appropriate concentration was directly added to $360 \mu \mathrm{l}$ sporangial suspension $\left(\mathrm{ca} .3 \times 10^{4} / \mathrm{ml}\right.$ ) or motile zoospore suspension (ca. $1 \times 10^{5} / \mathrm{ml}$ ) of $P$. viticola taken in a cavity of a plant tissue culture multi-well plate to make a final volume of $400 \mu \mathrm{l}$ and then quickly mixed with a glass rod. The final concentration of DMSO in the sporangia or zoospore suspension never exceeded $1 \%(\mathrm{v} / \mathrm{v})$, a condition that does not affect zoosporogenesis or zoospore motility. A $1 \%$ aqueous DMSO solution was used as control. The number of released zoospores per milliliter in the presence of varying doses of test compounds was counted in a hemocytometer $6 \mathrm{~h}$ after treatment. The number of released zoospores under different treatments of DAPG and its derivatives was estimated following protocols described earlier (Islam et al. 2007).

The motility inhibition, lysis and germination of zoospores at varying doses of the test compounds were observed under a light microscope at $10 \times$ magnification. Quantification of time-course of motility inhibition, lysis and germination of zoospores were carried out as described earlier (Islam et al. 2002). Each treatment was replicated three times. The mean values $\pm \mathrm{SE}$ (standard error) of percentage motility inhibition, and lysed and germinated zoospores in each treatment were calculated.

\section{Results}

Suppressed release of $P$. viticola zoospores from sporangia by phloroglucinol derivatives

The mature freshly harvested and washed lemon-shaped sporangia (ca. $3 \times 10^{4} / \mathrm{ml}$ ) of $P$. viticola released biflagellate motile zoospores $\left(\mathrm{ca} .1 \times 10^{5} / \mathrm{ml}\right)$ in sterilized tap water within 4-6 h incubation at room temperature (Fig. 2). During this process, called zoosporogenesis (Fig. 2c), three to five motile zoospores were released from each sporangium leaving the empty envelope (Fig. 2d). We evaluated the effect of 2,4-diacetylphloroglucinol (DAPG) and its four derivatives namely, phloroglucinol (PG), monoacetylphloroglucinol (MAPG), triacetylphloroglucinol (TAPG) and dipropylphloroglucinol (DPPG) on zoosporogenesis of P. viticola (Fig. 1).

All phloroglucinol derivatives suppressed the release of P. viticola zoospores from sporangia in a dose-dependent manner (Table 1). Among them, DPPG displayed the<smiles>CC(=O)c1c(O)cc(O)cc1O</smiles><smiles>CC(=O)c1c(O)cc(O)c(C(C)=O)c1O</smiles>

Phloroglucinol (PG)

Monoacetylphloroglucinol (MAPG)

Diacetylphloroglucinol (DAPG)<smiles>CC(=O)c1c(O)c(C(C)=O)c(O)c(C(C)=O)c1O</smiles><smiles>CCC(=O)c1c(O)cc(O)c(C(=O)CC)c1O</smiles>

Triacetylphloroglucinol (TAPG)

Dipropylphloroglucinol (DPPG) 

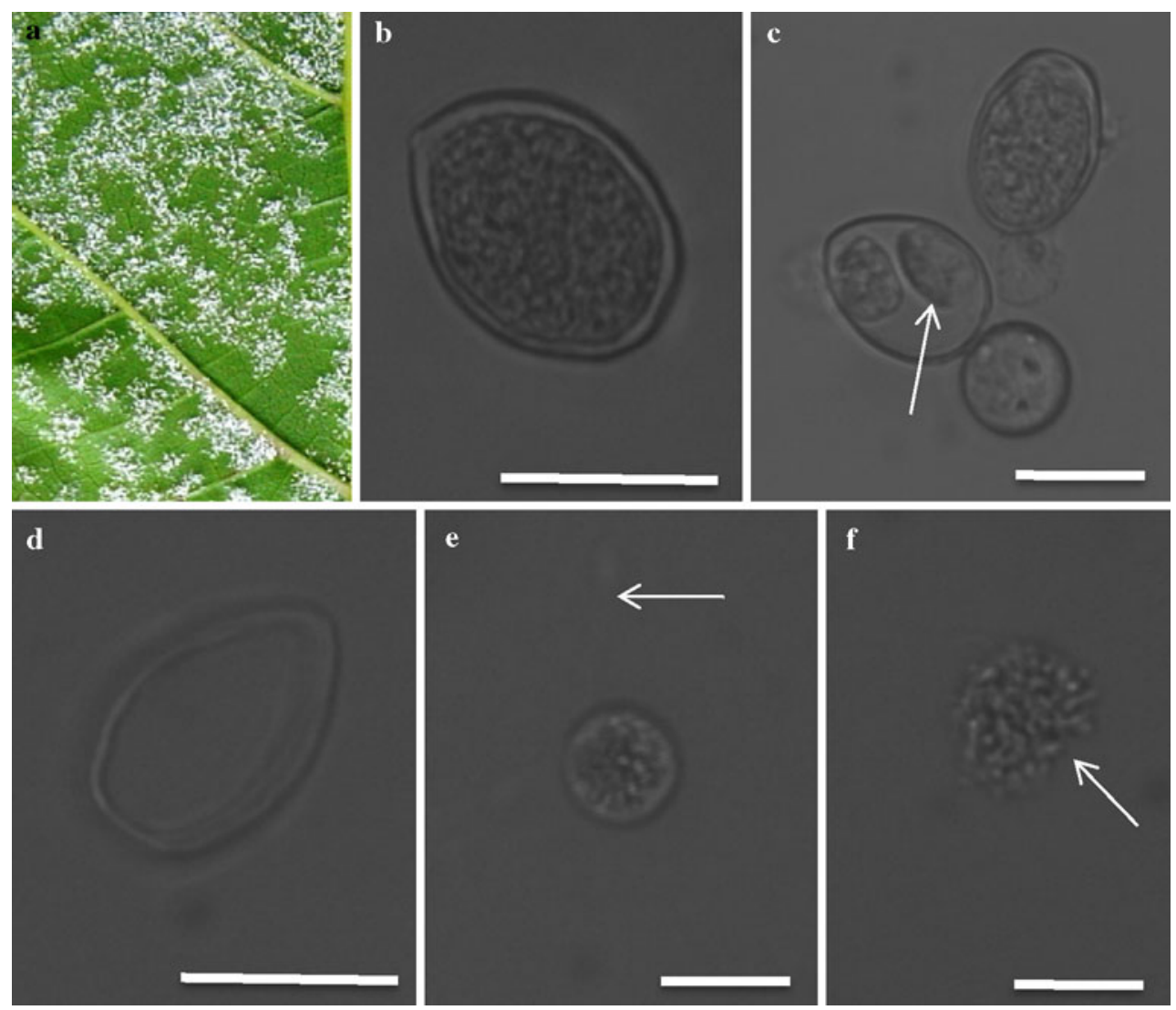

Fig. 2 Sporangial growth on a grapevine leaf (a) and light micrographs (b-f) showing a mature sporangium (b), releasing zoospores from a sporangium (c), an empty case (ghost) of a sporangium (d), a biflagellate zoospore (e) and a lysed zoospore (f). The white structures on grapevine leaves in a were $P$. viticola sporangia on branched sporangiophores. The photograph was taken 6 days after inoculation of a grapevine leaf with $1 \times 10^{3}$ sporangia/ml followed by incubation at $25^{\circ} \mathrm{C}$ in a growth chamber (16/8 light) at $95 \%$ relative humidity (Islam and Tiedeman 2008). (b) A mature sporangium which was just harvested from a. c Zoospores (arrow) formed inside a sporangium which was incubated in sterilized water for $6 \mathrm{~h}$ at $23^{\circ} \mathrm{C}$ in dark. (d) An empty case (ghost) of a sporangium

highest inhibition of zoospore release from sporangia. At $3 \mu \mathrm{g} / \mathrm{ml}$, DPPG completely blocked the process of zoosporogenesis followed by DAPG $(25 \mu \mathrm{g} / \mathrm{ml})$, TAPG $(25 \mu \mathrm{g} /$ $\mathrm{ml})$ and MAPG (100 $\mu \mathrm{g} / \mathrm{ml})$ (Table 1$)$. In contrast, PG only partially inhibited zoosporogenesis and at relatively high dose $(200 \mu \mathrm{g} / \mathrm{ml})$. Even when zoosporogenesis was completely blocked, the sporangia of $P$. viticola remained unburst even at the highest tested concentrations of DAPG or its derivatives.

Motility inhibition and lysis of $P$. viticola zoospores caused by DAPG and its derivatives

In sterilized water, the normal zoospores of $P$. viticola swam for several hours in a helical fashion. However, after release of zoospores. e A biflagellate motile zoospore (arrow indicates trace of a flagellum). f Lysed zoospores $60 \mathrm{~min}$ after treatment with DAPG at $20 \mu \mathrm{g} / \mathrm{ml}$. Pure DAPG (dissolved in small quantity of DMSO) at the concentration tested immediately caused inhibition of the motility of zoospores (see Table 2; "Materials and methods" for details of the bioassay). The halted zoospores rapidly settled to the bottom of the dish and then started to burst or lysed. The final concentration of DMSO in the aqueous solution alone (final concentration, $1 \%$ ) was used as negative control and caused no motility inhibition and lysis of zoospores. White bars in the b-f indicate $10 \mu \mathrm{m}$

zoospores released in the presence of phloroglucinols, swam very slowly or spun in tight circles or lysed depending on the doses of the test compound (Table 1).

Motility of zoospores is critical for disease cycles and virulence of the peronosporomycete phytopathogens. The phloroglucinol DAPG and its derivatives exhibited motility inhibitory activity followed by lysis of P. viticola zoospores in a dose- and time-dependent manner (Table 2). The minimum inhibitory concentration (MIC) for motility inhibition of zoospores by DAPG was $10 \mu \mathrm{g} / \mathrm{ml}$. At $20 \mu \mathrm{g} /$ $\mathrm{ml}$ concentration, DAPG completely inhibited motility of zoospores within $45 \mathrm{~min}$. All these immobilized zoospores lysed within $60 \mathrm{~min}$ (Fig. 2f). Initially, DAPG treated zoospores swam very slowly and/or spun in tight circles in a jerky fashion, and finally lysed (Fig. 2f). Among the 
Table 1 Effects of DAPG and other phloroglucinol derivatives on the release of Plasmopara viticola zoospores

\begin{tabular}{|c|c|c|c|}
\hline \multirow[t]{2}{*}{ Compound } & \multirow[t]{2}{*}{ Dose $(\mu \mathrm{g} / \mathrm{ml})$} & \multicolumn{2}{|c|}{ Relative percent of released zoospores $(\% \pm \mathrm{SE})^{\mathrm{a}}$ and their behaviors } \\
\hline & & Zoospores & Behaviors or fate of released zoospores \\
\hline \multirow[t]{4}{*}{ PG } & 50 & $98 \pm 3$ & Normal swimming \\
\hline & 100 & $62 \pm 7$ & Normal swimming \\
\hline & 150 & $52 \pm 9$ & Swam at lower than normal speed \\
\hline & 200 & $39 \pm 10$ & Swam at lower speed and $30 \%$ zoospores encysted \\
\hline \multirow[t]{4}{*}{ MAPG } & 15 & $98 \pm 3$ & Almost normal speed of swimming \\
\hline & 25 & $52 \pm 9$ & Swam at lower than normal speed \\
\hline & 50 & $15 \pm 4$ & $53 \%$ of released zoospores encysted or burst \\
\hline & 100 & $0 \pm 0$ & - \\
\hline \multirow[t]{4}{*}{ DAPG } & 5 & $98 \pm 1$ & Swam slowly in tight circle or jerky and $32 \%$ encysted \\
\hline & 10 & $70 \pm 8$ & Few zoospores $(2 \%)$ were motile and others encysted and burst \\
\hline & 15 & $3 \pm 1$ & All encysted and burst \\
\hline & 25 & $0 \pm 0$ & - \\
\hline \multirow[t]{5}{*}{ TAPG } & 1 & $95 \pm 5$ & Swam very slow with turning and $40 \%$ zoospores encysted \\
\hline & 5 & $69 \pm 6$ & Few (20\%) swam with low speed and others encysted or burst \\
\hline & 10 & $31 \pm 7$ & Few $(4-5 \%)$ swam with very slowly and others encysted and burst \\
\hline & 15 & $15 \pm 3$ & All zoospores encysted and burst \\
\hline & 25 & $0 \pm 0$ & - \\
\hline \multirow[t]{5}{*}{ DPPG } & 0.5 & $94 \pm 4$ & Normal swimming \\
\hline & 1.0 & $81 \pm 7$ & Only $40 \%$ swam in slower speed and rests encysted, few (10\%) burst \\
\hline & 1.5 & $46 \pm 9$ & Very few $(8 \%)$ swam, and others encysted and/or burst (50\%) \\
\hline & 2.0 & $26 \pm 5$ & Only $1-2 \%$ swam and others encysted and burst \\
\hline & 3.0 & $0 \pm 0$ & - \\
\hline
\end{tabular}

$P G$ phloroglucinol, $\quad M A P G$ monoacetylphloroglucinol, $D A P G$ diacetylphloroglucinol, $T A P G$ triacetylphloroglucinol, $D P P G$ dipropylphloroglucinol

${ }^{\mathrm{a}}$ Data presented here are average value $\pm \mathrm{SE}$ of at least three replications in each dose of compound

tested compounds, DPPG showed the highest inhibitory and lytic activities on zoospores followed by TAPG, DAPG, MAPG and PG. The un-substituted phloroglucinol (PG) was significantly less toxic to the zoospores of $P$. viticola as it only slightly affected their motility at $100 \mu \mathrm{g} / \mathrm{ml}$. Microscopic observation revealed that the behavioral and morphological changes of zoospores in the presence of all phloroglucinol derivatives were similar. In all cases, immobilized zoospores immediately lysed instead of undergoing encystment.

\section{Effects of DAPG on Aphanomyces cochlioides}

To see whether inhibitory effects of DAPG and its derivatives on zoosporogenesis and motility of zoospores are common phenomena against Peronosporomycetes, we included a soilborne peronosporomycete A. cochlioides in our bioassay. As expected, DAPG and its derivatives also suppressed zoosporogenesis and impaired motility of $A$. cochlioides zoospores in a similar manner. The bioassay revealed that $A$. cochlioides zoospores are slightly less sensitive to DAPG than those of P. viticola (Fig. 3). The doses required for equivalent suppression of zoosporogenesis in $A$. cochlioides were approximately 1.5 -fold higher than those of $P$. viticola (data not shown). Although all DAPG-inhibited $P$. viticola zoospores were finally lysed, only a small fraction of immobilized A. cochlioides zoospores were lysed. In A. cochlioides, the immobilized zoospores converted to round cystospores followed by germination to form germ tubes (Fig. 4). Among the tested compounds, DPPG displayed the highest motility inhibitory and lytic activities against $A$. cochlioides zoospores. Almost $100 \%$ of motile zoospores were halted and subsequently lysed at 40 and $5 \mu \mathrm{g} / \mathrm{ml}$ of DAPG and DPPG, respectively (Fig. 3). However, more than $50 \%$ of halted zoospores were converted to cystospores, which subsequently germinated in the presence of DAPG and DPPG at 20 and $2 \mu \mathrm{g} / \mathrm{ml}$, respectively. Interestingly, the germ tubes of these cystospores were excessively branched compared to the untreated control (Fig. 4). These results indicate that DAPG and its derivatives not only inhibit zoosporogenesis and the motility of zoospores but also impair the polar growth of the germ tubes growing from A. cochlioides cystospore. 
Table 2 Motility inhibitory and zoosporicidal activity of DAPG and its derivatives against the downy mildew pathogen Plasmopara viticola

\begin{tabular}{|c|c|c|c|c|c|c|c|c|c|}
\hline \multirow[t]{3}{*}{ Compound } & \multirow[t]{3}{*}{ Dose $(\mu \mathrm{g} / \mathrm{ml})$} & \multicolumn{8}{|c|}{ Motility inhibitory and zoosporicidal activity $(\% \pm \mathrm{SE})^{\mathrm{a}}$} \\
\hline & & \multicolumn{2}{|c|}{$15 \min$} & \multicolumn{2}{|c|}{$30 \mathrm{~min}$} & \multicolumn{2}{|c|}{$45 \mathrm{~min}$} & \multicolumn{2}{|c|}{$60 \mathrm{~min}$} \\
\hline & & $\begin{array}{l}\text { Inhibited } \\
\text { motility }\end{array}$ & Lysed & $\begin{array}{l}\text { Inhibited } \\
\text { motility }\end{array}$ & Lysed & $\begin{array}{l}\text { Inhibited } \\
\text { motility }\end{array}$ & Lysed & $\begin{array}{l}\text { Inhibited } \\
\text { motility }\end{array}$ & Lysed \\
\hline \multirow[t]{3}{*}{ PG } & 1 & $0 \pm 0$ & $0 \pm 0$ & $0 \pm 0$ & $0 \pm 0$ & $0 \pm 0$ & $0 \pm 0$ & $0 \pm 0$ & $0 \pm 0$ \\
\hline & 10 & $0 \pm 0$ & $0 \pm 0$ & $0 \pm 0$ & $0 \pm 0$ & $7 \pm 1$ & $0 \pm 0$ & $11 \pm 3$ & $3 \pm 1$ \\
\hline & 100 & $0 \pm 0$ & $0 \pm 0$ & $21 \pm 0$ & $0 \pm 0$ & $37 \pm 9$ & $9 \pm 2$ & $42 \pm 5$ & $12 \pm 4$ \\
\hline \multirow[t]{4}{*}{ MAPG } & 1 & $0 \pm 0$ & $0 \pm 0$ & $0 \pm 0$ & $0 \pm 0$ & $0 \pm 0$ & $0 \pm 0$ & $0 \pm 0$ & $0 \pm 0$ \\
\hline & 10 & $0 \pm 0$ & $0 \pm 0$ & $0 \pm 0$ & $0 \pm 0$ & $18 \pm 3$ & $6 \pm 1$ & $47 \pm 5$ & $18 * * \pm 0$ \\
\hline & 50 & $30 \pm 6$ & $9 \pm 2$ & $72 \pm 5$ & $39 \pm 3$ & $76 \pm 10$ & $42 \pm 4$ & $82 \pm 7$ & $58 \pm 7$ \\
\hline & 100 & $100 \pm 0$ & $100 \pm 0$ & nt & $\mathrm{nt}$ & nt & $\mathrm{nt}$ & $\mathrm{nt}$ & $\mathrm{nt}$ \\
\hline \multirow[t]{5}{*}{ DAPG } & 1 & $0 \pm 0$ & $0 \pm 0$ & $0 \pm 0$ & $0 \pm 0$ & $0 \pm 0$ & $0 \pm 0$ & $0 \pm 0$ & $0 \pm 0$ \\
\hline & 10 & $0 \pm 0$ & $0 \pm 0$ & $13 \pm 3$ & $0 \pm 0$ & $21 \pm 4$ & $5 \pm 1$ & $29 \pm 5$ & $17^{*} \pm 4$ \\
\hline & 15 & $72 \pm 9$ & $43 \pm 5$ & $93 \pm 10$ & $76 \pm 7$ & $95 \pm 4$ & $82 \pm 6$ & $98 \pm 3$ & $89 \pm 8$ \\
\hline & 20 & $92 \pm 4$ & $55 \pm 6$ & $100 \pm 0$ & $88 \pm 11$ & $100 \pm 0$ & $98 \pm 1$ & $100 \pm 0$ & $100 \pm 0$ \\
\hline & 25 & $100 \pm 0$ & $98 \pm 3$ & $100 \pm 0$ & $100 \pm 0$ & $\mathrm{nt}$ & $\mathrm{nt}$ & $\mathrm{nt}$ & nt \\
\hline \multirow[t]{5}{*}{ TAPG } & $1 *$ & $0 \pm 0$ & $0 \pm 0$ & $10 \pm 3$ & $0 \pm 0$ & $15 \pm 2$ & $5 \pm 1$ & $33 \pm 6$ & $18 \pm 3$ \\
\hline & $5^{*}$ & $20 \pm 3$ & $0 \pm 0$ & $41 \pm 5$ & $31 \pm 6$ & $68 \pm 8$ & $42 \pm 8$ & $73 \pm 10$ & $51 \pm 7$ \\
\hline & $10^{*}$ & $39 \pm 6$ & $8 \pm 2$ & $61 \pm 8$ & $44 \pm 5$ & $81 \pm 9$ & $61 \pm 6$ & $98 \pm 3$ & $76 \pm 10$ \\
\hline & 15 & $74 \pm 7$ & $21 \pm 6$ & $89 \pm 9$ & $65 \pm 9$ & $100 \pm 0$ & $90 \pm 7$ & $100 \pm 0$ & $100 \pm 0$ \\
\hline & 25 & $91 \pm 3$ & $80 \pm 7$ & $100 \pm 0$ & $100 \pm 0$ & $\mathrm{nt}$ & $100 \pm 0$ & $\mathrm{nt}$ & $\mathrm{nt}$ \\
\hline \multirow[t]{4}{*}{ DPPG } & $1^{*}$ & $0 \pm 0$ & $0 \pm 0$ & $12 \pm 3$ & $0 \pm 0$ & $21 \pm 5$ & $0 \pm 0$ & $39 \pm 4$ & $18 \pm 3$ \\
\hline & 2 & $80 \pm 5$ & $68 \pm 8$ & $90 \pm 7$ & $72 \pm 8$ & $97 \pm 4$ & $82 \pm 5$ & $99 \pm 1$ & $86 \pm 7$ \\
\hline & 3 & $100 \pm 0$ & $85 \pm 11$ & $100 \pm 0$ & $99 \pm 2$ & $100 \pm 0$ & $100 \pm 0$ & $\mathrm{nt}$ & nt \\
\hline & 4 & $100 \pm 0$ & $100 \pm 0$ & $\mathrm{nt}$ & nt & $\mathrm{nt}$ & $\mathrm{nt}$ & $\mathrm{nt}$ & $\mathrm{nt}$ \\
\hline
\end{tabular}

nt not tested, $P G$ phloroglucinol, $M A P G$ monoacetylphloroglucinol, $D A P G$ diacetylphloroglucinol, TAPG triacetylphloroglucinol, $D P P G$ dipropylphloroglucinol

* Zoospores were moving very slowly with tight circle or jerky movement

** Only larger zoospores stopped and lysed

${ }^{a}$ Data presented here are average value \pm SE of at least three replications in each dose of compound

\section{Discussion}

In this study, we have shown that a polyketide antibiotic, DAPG, produced by a biocontrol bacterium, $P$. fluorescens, inhibits zoosporogenesis and impairs the motility of $P$. viticola and A. cochlioides zoospores in a dose-dependent manner (Tables 1, 2; Fig. 3). Compounds structurally related to DAPG also displayed similar biological activities against these two tested peronosporomycetes but at varying doses. DAPG is produced by many strains of the biocontrol bacterium, $P$. fluorescens, which is known to exert inhibitory effects against many microorganisms including the hyphal growth of the phytopathogens A. cochlioides and Pythium ultimum var. sporangifera (de Souza et al. 2003a; Islam and Fukushi 2010). This is the first report of suppression of zoosporogenesis and inhibition of motility of zoospores by DAPG and its derivatives against the obligate biotrophic grapevine downy mildew pathogen, $P$. viticola and a damping-off pathogen $A$. cochlioides.

One of the novel findings of the present study includes inhibition of zoosporogenesis in two important peronosporomycete phytopathogens by DAPG and some of its derivatives at micromolar concentration (Table 1; Fig. 2). $\mathrm{Ca}^{2+}$ at millimolar concentrations has been found essential for zoosporogenesis (Islam and Tahara 2001). Although, the mechanism of zoosporogenesis in peronosporomycetes is poorly understood, the multiple roles of cytoskeletal actin in formation and architecture of Saprolegnia ferax and Achlya bisexualis (peronosporomycetes) zoospores have been demonstrated (Heath and Harold, 1992). Recently, we found that DAPG-induced excessive branching and inhibition of polar growth of A. cochlioides hyphae are linked to the disruption of cytoskeletal actins in the hyphal cells (Islam and Fukushi 2010). Therefore, 

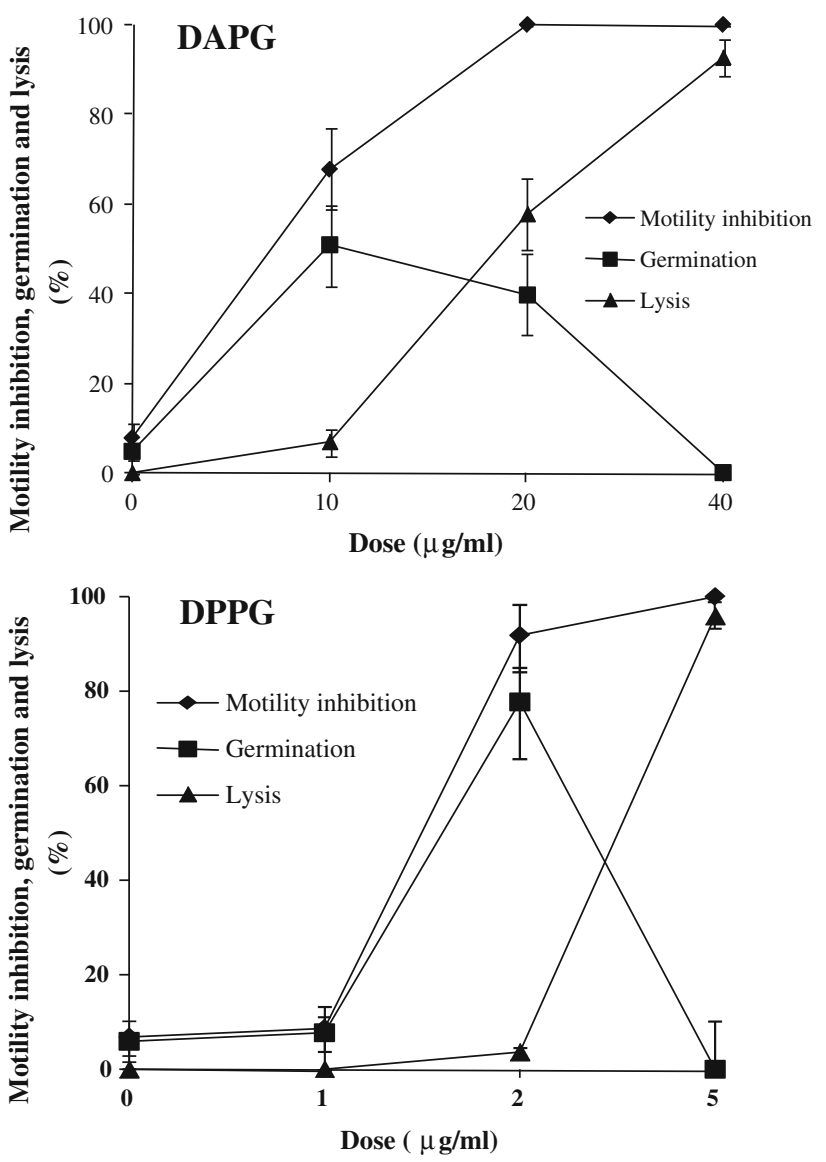

Fig. 3 Effects of diacetylphloroglucinol (DAPG) and dipropylphloroglucinol (DPPG) on motility inhibition, lysis and germination of Aphanomyces cochlioides. DAPG or DPPG were first dissolved in a small quantity of DMSO and then serially diluted with distilled water. Appropriate amounts of a sample suspension were added to the aqueous zoospore suspension. The final DMSO concentration was always less than $1 \%$ in the zoospore suspension. The time course of changes of zoospores was observed microscopically (magnification $\times 20$ ) for up to $1 \mathrm{~h}$ after the treatment, and the percentages of activity were calculated as described previously (Islam et al. 2005). DMSO alone (final concentration in the zoospore suspension, 1\%) was used as the control and did not cause any motility inhibition and lysis of the zoospores. The data are the averages \pm standard errors of at least three replications for each dose of the tested compound suppression of zoosporogenesis by DAPG shown in this report might also be associated with the disruption of actins in the differentiation of sporangia. However, DAPG has recently been reported to inhibit the mitochondrial function in yeast (Gleeson et al. 2010). As cleavage of nuclei and dramatic differentiation of sporangia during zoosporogenesis require supply of energy from the mitochondria, impairment of the mitochondrial function in sporangia by DAPG might be associated with suppression of zoospore release.

We found that DAPG and its derivatives impaired the motility of both $P$. viticola and $A$. cochlioides zoospores in a dose- and time-dependent manner (Table 2; Fig. 3). Furthermore, all immobilized zoospores of $P$. viticola were lysed (Figs. 2, 3). Motility inhibitory and lytic activities of DAPG in Pythium ultimum var. sporangifera zoospores have been reported (de Souza et al. 2003a). The dose required for motility inhibition and disintegration of $P$. ultimum zoospores was only $0.8 \mathrm{ng} / \mathrm{ml}$, which was much lower (1000-fold lower) than the doses of DAPG required for equivalent activity in $P$. viticola zoospores $(10 \mu \mathrm{g} / \mathrm{ml})$. Although the mechanism is unknown, the motility inhibitory activity of DAPG against an osmotrophic amoeba Vahlkampfia sp. has also been reported (Jousset et al. 2006). Several natural products such as rhamnolipids (Kim et al. 2000), anacardates (Begum et al. 2002), nicotinamide (Shimai et al. 2002; Islam et al. 2004), polyflavonoid tannins (Islam et al. 2002), cyclic lipopeptides (de Souza et al. 2003b), and xanthobaccins (Islam et al. 2005; Islam 2008) have also been shown to have motility inhibitory activities against peronosporomycete zoospores. In most of these cases, the immobilized zoospores were lysed except in the case of nicotinamide, where halted A. cochlioides zoospores developed to round cystospores which were converted into zoospores within $3 \mathrm{~h}$ (Islam et al. 2004).

Recently, Gleeson et al. (2010) demonstrated that DAPG produced by $P$. fluorescens impairs the mitochondrial function in the yeast Saccharomyces cerevisiae. As
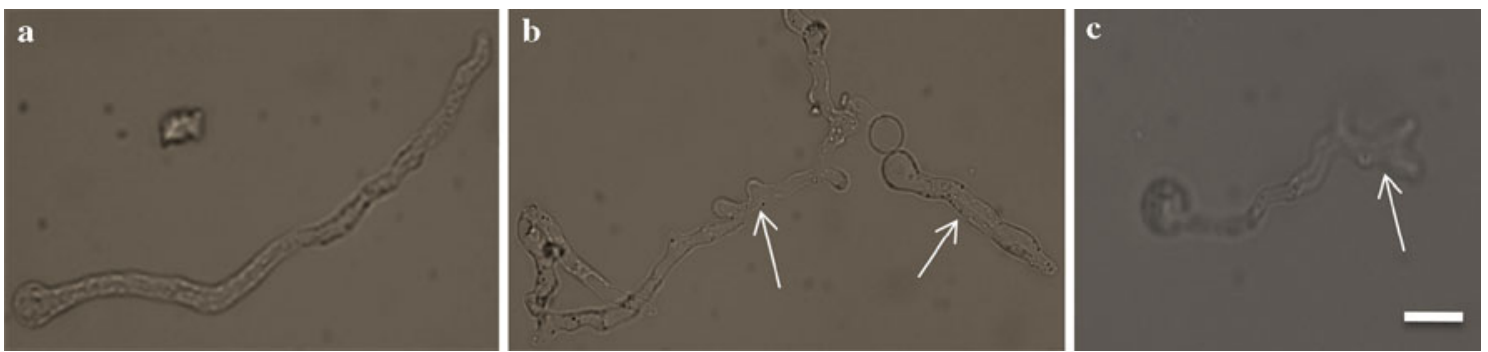

Fig. 4 Micrographs showing effects of DAPG on the morphology of germ tubes of Aphanomyces cochlioides. a An unbranched long germ tube (control); b two germinated cystospores with excessively branched, curled or poorly elongated germ tubes $(40 \mu \mathrm{g} / \mathrm{ml})$ and $\mathbf{c}$ a germinated cystospore with hyperbranched and curled germ tube (40 $\mu \mathrm{g} / \mathrm{ml})$. White bar, $10 \mu \mathrm{m}$ for all micrographs 
peronosporomycete zoospores cannot absorb nutrients from the medium, they use internal preserved energy for their motility. Therefore, impairment of motility of zoospores by DAPG shown in this report might be associated with disruption of steady energy supply from mitochondria to the motile cells. However, a further study is needed to test this hypothesis. Although the underlying molecular mechanism of motility of zoospores is not fully elucidated, silencing of the $\mathrm{G} \alpha$ subunit gene Pigpal in Phytophthora infestans resulted in transformants, which produced zoospores with severely impaired motility (Latijnhouwers et al. 2004). These zoospores were also less virulent in infecting potato plants than those of the wild type.

In both the zoosporogenesis and zoospore motility bioassays, phloroglucinol derivatives displayed similar consistent inhibitory effects against the grapevine downy mildew pathogen $P$. viticola and the sugar beet dampingoff pathogen A. cochlioides (Tables 1, 2; Figs. 2, 3). According to the bioassay results, the activities of the tested compounds ranked DPPG $>$ TAPG $>$ DAPG $>$ MAPG $>$ PG for both zoosporogenesis and motility inhibition of the zoospores. It appeared that (1) the degree of substitution of hydrogen atoms in the benzene ring of phloroglucinol by acyl groups (acetyl or propyl) increased bioactivity; and (2) substitution with a larger aliphatic group (propyl) showed higher activity than the shorter aliphatic group (acetyl). This report, for the first time, elaborates our understanding on the structure-activity relationships of polyketide antibiotic DAPG against peronosporomycete zoospores (de Souza et al. 2003a). For establishment of detail structure-activity relationships, a further study is needed with a larger number of DAPG derivatives and zoospores from diverse species of the peronosporomycetes.

Another noteworthy observation was that cystospores produced in the presence of DAPG germinated with excessively branching germ tubes (Fig. 4). This result indicates that DAPG and its derivatives not only inhibit zoosporogenesis and motility of zoospores but also impair polar growth of the germ tubes. In our previous research, we demonstrated that DAPG inhibits hyphal growth by inducing excessive branching, which was linked to the disruption of the filamentous actin organization in the hyphal cells of $A$. cochlioides (Islam and Fukushi 2010). Therefore, it is reasonable to assume that the hyperbranching observed in DAPG affected germ tubes (Fig. 4) is linked to the disruption of F-actin in the cells of germ tubes by DAPG. Disruption of the cytoskeletal network associated with excessive branching and curling of hyphae of a damping-off pathogen, A. cochlioides, by the biocontrol bacterium Lysobacter sp. strain SB-K88 has been demonstrated (Islam 2008).
Both synergistic and antagonistic interactions between prokaryotic and eukaryotic microorganisms are found in a myriad of environments. In this paper, we have demonstrated that an antibiotic, DAPG, produced by a prokaryotic bacterium, $P$. fluorescens, disrupts two specific asexual life cycle stages (zoosporogenesis and motility of zoospores) in two eukaryotic phytopathogens, $P$. viticola and A. cochlioides, belonging to the kingdom of Straminipila. Although the mechanism is not clear at present, these antagonistic activities of DAPG and its derivatives against peronosporomycetes might be associated with the impairment of the mitochondrial function and/or disruption of the actin organization in the respective cells (Heath and Harold 1992; Gleeson et al. 2010). Our easy production method of sporangia and copious amounts of zoospores of the obligate biotrophic grapevine downy mildew pathogen, $P$. viticola, in a host-free system would facilitate to dissect the underlying molecular mechanism of inhibitory effects of DAPG against zoosporogenesis and motility of this notorious peronosporomycete phytopathogen.

Acknowledgments We are thankful to Alexander von Humboldt Foundation for Georg Forster Research Fellowship (to MTI) and financial supports for the research. Dr. Yukiharu Fukushi, Laboratory of Ecological Chemistry of Hokkaido University, Japan deserves our sincere thanks for kindly providing synthetic DAPG and its derivatives. We are also very thankful to Prof. Beate Berkelmann, Geisenheim Research Center, Germany and Sugar Beet Research Institute (IFZ), Goettingen, Germany for kindly providing Plasmopara viticola and Aphanomyces cochlioides, respectively for this research. Dr. P. Facey of University of West Indies, Jamaica, deserves our appreciation for linguistic editing of this manuscript.

\section{References}

Agrios GN (1997) Plant Pathology. Academic Press, San Diego

Bangera MG, Thomashow LS (1999) Characterization of a gene cluster for synthesis of the polyketide antibiotic 2,4-diacetylphloroglucinol from Pseudomonas fluorescens Q2-87. J Bacteriol 181:3155-3163

Begum P, Hashidoko Y, Islam MT, Ogawa Y, Tahara S (2002) Zoosporicidal activities of anacardic acids against Aphanomyces cochlioides. Z Naturforsch 57c:874-882

Bender CL, Rangaswamy V (1999) Polyketide production by plantassociated Pseudomonads. Ann Rev Phytopathol 37:175-196

Brazelton JN, Pfeufer EE, Sweat TA, Brian B, Gardener M, Coenen C (2008) 2,4-diacetylphloroglucinol alters plant root development. Mol Plant Microbe Interact 21:1349-1358

de Souza JT, Arnould C, Deulvot C, Lemanceau P, GianinazziPearson V, Raaijmakers JM (2003a) Effect of 2,4-diacetylphloroglucinol on Pythium: cellular responses and variation in sensitivity among propagules and species. Phytopathology 93:966-975

de Souza JT, de Boer M, de Waard P, van Beek TA, Raaijmakers JM (2003b) Biochemical, genetic, and zoosporicidal properties of cyclic lipopeptide surfactants produced by Pseudomonas fluorescens. Appl Environ Microbiol 69:7161-7172 
Dwivedi D, Johri BN (2003) Antifungals from fluorescent pseudomonads: biosynthesis and regulation. Curr Sci 85:1693-1703

Gleeson O, O'Gara F, Morrissey JP (2010) The Pseudomonas fluorescens secondary metabolite 2,4-diacetylphloroglucinol impairs mitochondrial function in Saccharomyces cerevisae. Antonie van Leeuwenhoek 97:261-273

Heath IB, Harold RL (1992) Actin has multiple roles in the formation and architecture of zoospores of the oomycetes, Saprolegnia ferax and Achlya bisexualis. J Cell Sci 102:611-627

Islam MT (2008) Disruption of ultrastructure and cytoskeleton network is involved with biocontrol of damping-off pathogen Aphanomyces cochlioides by Lysobacter sp. SB-K88. Biol Contr 46:312-321

Islam MT, Fukushi Y (2010) Growth inhibition and excessive branching in Aphanomyces cochlioides induced by 2,4-diacetylphloroglucinol is linked to disruption of filamentous actin cytoskeleton in the hyphae. World J Microbiol Biotechnol 26:1163-1170

Islam MT, Tahara S (2001) Chemotaxis of fungal zoospores, with special reference to Aphanomyces cochlioides. Biosci Biotechnol Biochem 65:1933-1948

Islam MT, Tiedeman Av (2008) Zoosporogenesis and differentiation of grapevine downy mildew pathogen Plasmopara viticola in host-free system. Phytopathology 98:S72

Islam MT, Ito T, Sakasai M, Tahara S (2002) Zoosporicidal activity of polyflavonoid tannin identified in Lannea coromandelica stem bark against phytopathogenic oomycete Aphanomyces cochlioides. J Agric Food Chem 50:6697-6703

Islam MT, Hashidoko Y, Ito T, Tahara S (2004) Interruption of the homing events of phytopathogenic Aphanomyces cochlioides zoospores by secondary metabolites from nonhost Amaranthus gangeticus. J Pestic Sci 29:6-14

Islam MT, Hashidoko Y, Deora A, Ito T, Tahara S (2005) Suppression of damping-off disease in host plants by the rhizoplane bacterium Lysobacter sp. strain SB-K88 is linked to plant colonization and antibiosis against soilborne Peronosporomycetes. Appl Environ Microbiol 71:3776-3786

Islam MT, Sakasai M, Hashidoko Y, Deora A, Sakihama Y, Tahara S (2007) Composition of culture medium influences zoosporogenesis and differentiation of Aphanomyces cochlioides. J Gen Plant Pathol 73:324-329

Isnansetyo A, Cui L, Hiramatsu K, Kamei Y (2003) Antibacterial activity of 2,4-diacetylphloroglucinol produced by Pseudomonas sp. AMSN isolated from a marine alga, against vancomycinresistant Staphylococcus aureus. Int J Antimicrob Agents 22:545-547

Jousset A, Lara E, Wall LG, Valverde C (2006) Secondary metabolites help biocontrol strain Pseudomonas fluorescens
CHA0 to escape protozoan grazing. Appl Environ Microbiol 72:7083-7090

Judelson HS, Blanco FA (2005) The spores of Phytophthora: weapons of plant destroyer. Nat Rev Microbiol 3:47-58

Kamei Y, Isnansetyo A (2003) Lysis of methicillin-resistant Staphylococcus aureus by 2,4-diacetylphloroglucinol produced by Pseudomonas sp. AMSN isolated from a marine alga. Int $\mathrm{J}$ Antimicrob Agents 21:71-74

Kiefer B, Riemann M, Kassemeyer CBH, Nick P (2002) The host guides morphogenesis and stomatal targeting in the grapevine pathogen Plasmopara viticola. Planta 215:387-393

Kim BS, Lee JY, Hwang BK (2000) In vivo control and in vitro antifungal activity of rhamnolipid B, a glycolipid antibiotic, against Phytophthora capsici and Colletotrichum orbiculare. Pest Manag Sci 56:1029-1035

Latijnhouwers M, Ligterink W, Vleeshouwers VGAA, van West P, Govers F (2004) A G-alpha subunit controls zoospore motility and virulence in the potato late blight pathogen Phytophthora infestans. Mol Microbiol 51:925-936

Marchand PA, Weller DM, Bonsall RF (2000) Convenient synthesis of 2,4-diacetylphloroglucinol, a natural antibiotic involved in the control of take-all disease of wheat. J Agric Food Chem 48:1882-1887

Paulsen IT, Press C, Ravel J, Kobayashi DY, Myers GSA, Mavrodi DV, DeBoy RT, Seshadri R, Ren Q, Madupu R, Dodson RJ, Durkin AS, Brinkac LM, Daugherty SC, Sullivan SA, Rosovitz MJ, Gwinn ML, Zhou L, Nelson WC, Weidman J, Watkins K, Tran K, Khouri H, Pierson EA, Pierson LS III, Thomashow LS, Loper JE (2005) Complete genome sequence of the plant commensal Pseudomonas fluorescens Pf-5: insights into the biological control of plant disease. Nat Biotechnol 23:873-878

Raudales RE, Stone E, McSpadden Gardener BB (2009) Seed treatment with 2,4-diacetylphloroglucinol-producing pseudomonads improves crop health in low-pH soils by altering patterns of nutrient uptake. Phytopathology 99:506-511

Riemann M, Buche C, Kassemmeyer H-H, Nick P (2002) Cytoskeletal responses during early development of the downy mildew of grapevine (Plasmopara viticola). Protoplasma 219:13-22

Shimai T, Islam MT, Fukushi Y, Hashidoko Y, Yokosawa R, Tahara S (2002) Nicotinamide and structurally related compounds show halting activity against zoospores of the phytopathogenic fungus Aphanomyces cochlioides. Z Naturforsch 57c:323-331

Weller DM, Landa BB, Mavrodi OV, Schroeder KL, de la Fuente L, Bankhead SB, Molar RA, Bonsall RF, Mavrodi DV, Thomashow LS (2007) Role of 2,4-diacetylphloroglucinol-producing fluorescent Pseudomonas spp. in the defense of plant roots. Plant Biol 9-4-20 